\title{
Biological Hazards Associated with Microblading and Evaluation of its Infection Control Procedures and Wound Care
}

\author{
Emily Wong ${ }^{1}$, Helen J. Heacock-Rivers ${ }^{2}$
}

1 Lead author, B. Tech Student, School of Health Sciences, British Columbia Institute of Technology, 3700 Willingdon Ave, Burnaby, BC V5G 3H2

2 Supervisor, School of Health Sciences, British Columbia Institute of Technology, 3700 Willingdon Ave, Burnaby, BC V5G 3H2

\begin{abstract}
Background: Microblading is emerging as one of the fastest growing beauty trends, appearing in tattoo shops, hair salons, and even in private home studios. The procedure uses a tool with single blade to penetrate the upper layer of the dermis and deposit semi-permanent pigments to mimic hair-like strokes. This study compares the risks of microblading to those in tattooing and analyzes the similarities in order to determine the biological hazards associated with microblading. Currently, there is a lack of knowledge on microblading practices specifically, and the purpose of this study was to evaluate the level of infection control knowledge and practices in place, as well as the attitudes towards regulations in British Columbia.

Method: Self-administered electronic surveys created on Google Forms were distributed to microblading establishments in B.C. through email. The survey assessed the knowledge, attitudes, and practices of microbladers in B.C. through a series of questions regarding demographics, infection control, and wound care. A list of 130 microblading establishments were contacted and asked to participate in the online survey.

Results: Among the 130 microblading establishments contacted, 41 agreed to participate. The majority of microbladers had a college certificate or diploma, 1-5 years of experience, and have taken a bloodborne pathogen course. Over $31 \%$ of the participants operated both in microblading as well as permanent makeup, $27 \%$ operated solely as microbladers, and $22 \%$ of the participants had both microblading and spa operations. The most prevalent form of training was a microblading course that lasted a week or longer, and $78 \%$ of the participants felt that there should be more training required for becoming a microblader. There was no association between the years of experience and level of pathogen knowledge according to the Chi square test $(\mathrm{p}=0.78)$, and no association between the attitude towards regulations regarding microblading and the number of infection control measures in place $(\mathrm{p}=0.38)$. However, there was a statistically significant association between taking a bloodborne pathogen course and knowing the correct bloodborne pathogens of concern.

Conclusion: Microbladers in British Columbia are fairly new and thus only have 1-5 years of experience, and minimal training of week-long microblading courses. A majority of them feel that more training or certification should be required and that there should be more regulations regarding microblading. The results indicated that education and training provide the most knowledge rather than years of experience. This suggests that health authorities should focus on providing more access to education for microblading, such as offering a TattooSafe program for tattooing microblading, and permanent makeup, similar to FoodSafe, and developing more material to inform microblading fact sheets.
\end{abstract}

Keywords: Microblading, microbladers, micropigmentation, semi-permanent makeup, permanent makeup, tattooing, infection control, regulations. 


\section{$\underline{\text { Introduction }}$}

Microblading, also known as eyebrow embroidery or eyebrow feathering, has become one of the most popular beauty trends in North America due to social media influences. The practice is a semi- permanent makeup technique which utilizes an instrument with a blade on the end that consists of a row of fine needles to create hair like strokes on eyebrows (1). Microblading produces a natural looking feathery brow as a result, which can last up to three years with minimal touchups.

As an increasing number of microblading services emerge, British Columbia's Health Authorities are in need of information on these types of personal service establishments; however, due to the recent nature of this service, in depth health and safety data is lacking. Due to the penetration of the blade into the skin to deposit pigment, microblading is recognized as a type of tattoo, and is subject to the same risks as tattooing. Infection control practices are critical to prevent endangering the public's health with communicable diseases such as hepatitis $\mathrm{C}$, $\mathrm{HIV}$, and skin infections related to tattooing and permanent makeup. However, little is known about what microblading services do to control for this aspect of the procedures even though they are exposed to the same risks.

The purpose of this research project was to investigate the infection control practices of microblading technicians in both salon establishments and non-regulated environments, to determine if their methods are effectively protecting the public against bloodborne pathogens and other communicable diseases.

In order to assess the knowledge and skills required for infection control, hazards, infection control and wound care associated with tattooing was analyzed and compared to the same aspects in microblading. This was used to evaluate the knowledge, practices, and attitudes of microbladers towards infection control and regulations.

\section{Literature Review}

\section{Bloodborne pathogens:}

The microblading procedure involves a blade comprised of several needles cutting small incisions into the dermal layer of the skin (1). This presents an opportunity for pathogens to enter the body and infect the individual if the procedure is not performed with sterile equipment. Some of the most prevalent infectious diseases associated with tattoos are Hepatitis B and C (HBV and HCV), nontuberculosis mycobacteria, and HIV (2).

While these diseases are considered high risk and life threatening, both Shinohara and Kluger compared different complications associated with tattooing and stated that due to improved aseptic techniques such as single-use disposable needles and hygiene regulations, the risks of contracting the diseases are minimal unless it is done in prisons or at home, where standards of hygiene may be lower $(3,4)$. Many studies have indicated that the use of single-use disposable needles has lowered the risk of disease transmission. The similarities for transmission risks in tattooing and microblading indicate that the bloodborne pathogens associated with tattooing can be listed as hazards in microblading fact sheets or guidelines.

\section{Skin Infections:}

Skin infections are a common risk with any type of cosmetic procedure involving direct skin contact. Microblading is exposed to similar dermal complications as tattooing as they are both performed on the epidermal and dermal layer of skin, and use pigments which may cause allergic reactions in some individuals (5).

Mycobacterial infections have caused numerous outbreaks in tattoo clients due to dilution of tattoo ink with tap water $(4,6)$. Giulieri et al. published a report of an outbreak of Mycobacterium haemophilum in 12 female patients after getting permanent makeup done on their eyebrows by a single artist (6). The cause was linked to the makeup ink and the possible contamination of it with tap water, demonstrating that using sterile water is critical to protect against infections (6). This would be a 
pertinent requirement for microblading guidelines, as the pigments may be diluted with water as well, and therefore it is critical for the microblading technicians to do it safely.

\section{Pigments:}

Pigments cause variable skin reactions, including hypersensitivity or allergies to pigments, which can be delayed by days to years. Ortiz and Alster highlight how the tattoo dyes are not approved by the FDA for injection under the skin, and therefore they are not actually approved for use, similar to Canada's Food and Drug Regulations, which follows the U.S. FDA guidelines $(7,8)$.

The lack of regulation and understanding of tattoo pigments presents a large knowledge deficit that should be addressed by promoting stricter regulation of tattoo pigments and holding them to a different standard than the pigments which sit on top of the skin and ensuring they are not made with toxigenic, carcinogenic, or mutagenic substances. This translates to the same concerns for microblading pigments and ensuring that they are made with nonhazardous materials and recommending stricter regulations as injected pigments separately from topical dyes.

\section{Infection Control Procedures:}

The infection control procedures of microblading are not well established in scientific literature; however, due to the similarities in the equipment and the public health risks associated with tattoos, the infection control procedures for tattooing can be applied to microblading as well. The most significant steps of preventing transmission of pathogens are cleaning, disinfecting, sterilizing, and using single-use disposable needles, as outlined in the BC Guidelines For Body Modifications (9). Needles and blades should be single-use disposables as they are the most effective way to prevent transmission of disease. An analysis of the infection control procedures for tattooing in the BC Guidelines for Body Modification suggests that the procedures can be a transition to microblading infection control procedures with little modification.
Training is also mentioned as a requirement in BC Guidelines for PSEs; this is a large issue in the microblading community. Currently, there is no official requirement for training for microblading services, therefore microblading technicians may lack education on communicable diseases and infection control practices as it relates to microblading (1).

\section{Wound Care:}

In microblading, a majority of clients are told to keep their eyebrows away from water and not touch them for up to 10 days, not wear makeup for a week, and apply the ointment or balm provided by the technician as their aftercare (10). The aftercare of open wounds is generally when most infections occur, due to contamination or improper care. An assessment of what type of wound care would be the most effective on small open wounds caused by microblading can reduce the chance of infection. Korting et al. found that the best method of minor wound care is to cleanse the area with potable water or saline solution, and apply hydroactive colloid gel in order to keep it moist (11). They also found that the moist environment provided the fastest healing time and restores the anatomic and functional integrity of the skin the most effectively, indicating that the most important step to microblading aftercare would be applying the ointment to keep it hydrated. The healing process of the long incisions made in microblading is substantially different from the tiny puncture wounds created by tattooing machines, and they would require completely different steps for aftercare. Therefore, tattoo aftercare knowledge cannot be translated to microblading aftercare knowledge and microblading should be treated as a minor open wound until more research can be done.

\section{Materials and Methods}

This research project was conducted through self-ministered web-based surveys for data collection. The survey was created using Google Forms, and results were recorded onto Google Spreadsheets and then exported onto Microsoft Excel (12). Access to Internet and a computer were required for participation in the survey. 
The results were analyzed using the Number Crunching Statistical System (NCSS) program (13). In addition, Microsoft Word was used to create a cover letter and consent form, which were provided to the potential participants to inform them of the purpose and obtain permission prior to administering the survey. An incentive was provided to participants, in the form of a BCIT prize draw, to encourage contribution.

The self-administered web-based survey was disseminated to microblading establishments in British Columbia through an email with the link to the Google Forms survey along with the cover letter and consent form. Participants were selected in a random sampling method, using Yelp and Google to find the listings of microblading establishments and emails were sent to their business emails (14). The survey was a KAP style survey, which assesses knowledge, attitude, and practices, and it consisted of close-ended questions designed to determine the demographics, years of experience, knowledge level, and practices in place at the establishments. Questions based on pathogen identification, disinfection and sterilization procedures, and aftercare instructions were included in the survey.

The survey data is collected automatically in Google Forms and the results were then transferred onto Microsoft Excel, which were then exported to NCSS for statistical analysis. Microsoft Excel was used to conduct the descriptive statistical analysis and inferential statistics were done using Chi square tests to interpret the data to determine if there was a relationship between the level of pathogen knowledge, years of experience, and the infection control practices in place.

\section{Inclusion and Exclusion Criteria:}

Any microblader actively practicing in $\mathrm{BC}$ was eligible to participate in the study. Those who did not provide consent and those who did not fit the inclusion criteria were excluded from the study.

\section{Ethical Considerations:}

The ethical implications in using human participants in the research study must be assessed to ensure no harm is done during the experiment. A cover letter and consent form were both provided to the participants prior to administering the survey. The cover letter informed them of the purpose of the study, how the data will be used, and the methods used to conduct the study. The consent form guaranteed confidentiality and the ability to withdraw consent at any time; it indicated that consent was voluntary (15). Administering of the survey could only be done after informed consent was achieved through clicking the "Yes" option to the consent question on the survey. The study was designed to cause no harm above what the daily risk of living for the participants is. As stated in the cover letter, the survey was submitted to and received ethics approval by the BCIT course instructor prior to distribution.

\section{$\underline{\text { Results }}$}

\section{Descriptive statistics:}

A total of forty-one microblading establishments participated in the survey and fit the inclusion criteria. In the first part of the survey, the individuals were asked a series of questions to ascertain their demographic details, such as level of education and years of experience, as seen in Table 1. The highest percentage of microbladers had a college certificate or diploma at $68.3 \%$ $(n=28)$, and $68.3 \%(n=28)$ of them had $1-5$ years of experience in microblading. It was also found that $85.4 \%(n=35)$ had previously taken a course on bloodborne pathogens. Their current activity in microblading was asked to ensure their qualification for the inclusion criteria; negative responses were not used for data collection. 
Table 1. Summary of demographics

\begin{tabular}{|l|l|l|l|l|l|}
\hline \multicolumn{2}{|l|}{$\begin{array}{l}\text { Highest level of } \\
\text { education }\end{array}$} & \multicolumn{2}{|l|}{ Years of experience } & \multicolumn{2}{l|}{$\begin{array}{l}\text { Taken a } \\
\text { bloodborne } \\
\text { pathogen } \\
\text { course }\end{array}$} \\
\hline $\begin{array}{lllll}\text { High school or } \\
\text { less }\end{array}$ & $\begin{array}{l}7.3 \% \\
(3)\end{array}$ & $\begin{array}{l}<1 \text { year of } \\
\text { experience }\end{array}$ & $\begin{array}{l}17.1 \% \\
(7)\end{array}$ & Yes & $\begin{array}{l}85.4 \% \\
(35)\end{array}$ \\
\hline $\begin{array}{l}\text { College } \\
\text { certificate or } \\
\text { diploma }\end{array}$ & $\begin{array}{l}68.3 \% \\
(28)\end{array}$ & $\begin{array}{l}1-5 \text { years } \\
\text { of } \\
\text { experience }\end{array}$ & $\begin{array}{l}68.3 \\
\%\end{array}$ & & \\
\hline $\begin{array}{l}\text { Undergraduate } \\
\text { degree }\end{array}$ & $\begin{array}{l}14.6 \% \\
(6)\end{array}$ & $\begin{array}{l}5 \text { or more } \\
\text { years of } \\
\text { experience }\end{array}$ & $\begin{array}{l}14.6 \% \\
(6)\end{array}$ & No & $\begin{array}{l}9.8 \% \\
(4)\end{array}$ \\
\cline { 1 - 1 } $\begin{array}{l}\text { Graduate } \\
\text { degree or } \\
\text { higher }\end{array}$ & $\begin{array}{l}9.8 \% \\
(4)\end{array}$ & & $\begin{array}{l}\text { Do } \\
\text { not } \\
\text { know }\end{array}$ & $\begin{array}{l}4.9 \% \\
(2)\end{array}$ \\
\hline
\end{tabular}

In addition, questions about where the microbladers operate, types of services they perform in their establishments, and what type of training they have received were asked to evaluate the type of experience microbladers have.

As seen in Figure 1, when asked what types of services microbladers perform in their establishments, many operators indicated that they do microblading and permanent makeup $(31.7 \%, \mathrm{n}=13)$, only microblading $(26.8 \%$, $\mathrm{n}=11)$, or microblading and spa services $(22 \%$, $\mathrm{n}=9$ ).

\section{Number of Different Types of Operations Microbladers} Perform

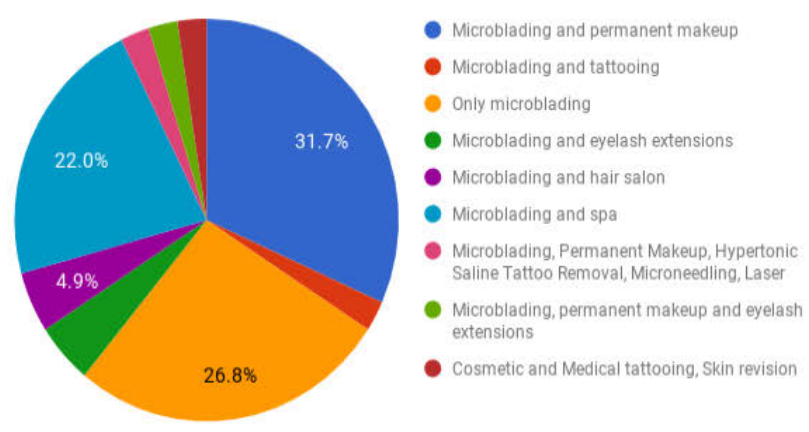

Figure 1. Types of different services provided by microbladers.
According to the results, $36.6 \%(n=15)$ of microbladers operate their business out of a private studio, $22 \%(\mathrm{n}=9)$ have their operations inside a spa, $17.1 \%(\mathrm{n}=7)$ operate inside a salon, and $12.2 \%(\mathrm{n}=5)$ work in a tattoo shop, as seen in Figure 2.

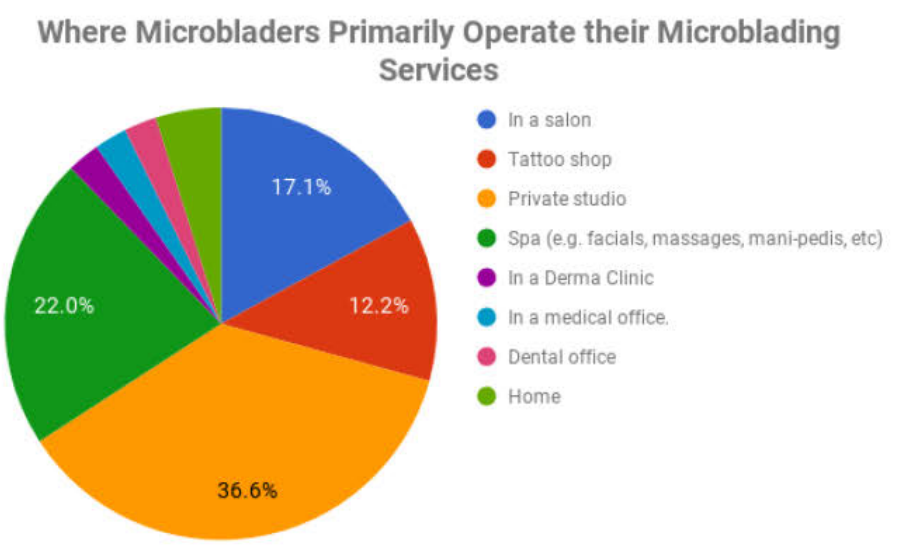

Figure 2. Types of places microbladers operate their services.

The most common type of training or certification received by microbladers was a microblading course than lasted more than one week $(20.5 \%, \mathrm{n}=8)$, followed by microblading workshops that were three days or less $(17.9 \%$, $\mathrm{n}=7$ ), and then the third most common was taking a microblading course in addition to cosmetology school $(10.3 \%, n=4)$.

The opinions of microbladers on the adequacy of the current training and certification requirements for microblading were also collected, and the majority indicated that they felt there needed to be more training required for microblading $(78.0 \%, \mathrm{n}=32)$. The remaining participants either specified "no" to more training required $(4.9 \%, \mathrm{n}=2)$, "no opinion" $(4.9 \%, n=2)$, or "it depends" $(12.2 \%, n=5)$, as seen in Figure 3. 
Opinion Of Microbladers Who Think There Should Be More Training Required For Microblading
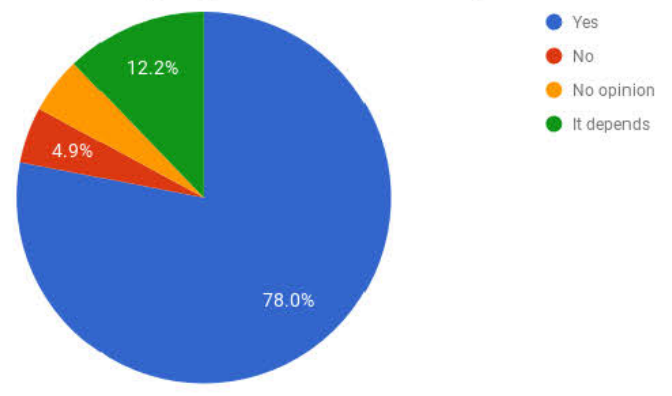

Figure 3. Opinions of microbladers on adequacy of training requirements.

The second portion of the survey assessed the level of knowledge, attitudes towards regulations, and types of infection control practices used in the microblading establishments.

When asked what type of sterilization method they used on their equipment, $51.2 \%(n=21)$ of microblading establishments answered that they used "single-use disposable microblading tools and chemical sterilant", $9.8 \%(\mathrm{n}=4)$ answered "single-use microblading tools" only, 7.3\% $(n=3)$ responded "single-use disposable microblading tools, chemical sterilant, and autoclave", $4.9 \%(\mathrm{n}=2)$ responded "single-use disposable microblading tools, chemical sterilant, and UV radiation", and the remaining $26.4 \%(n=11)$ responded with "single-use microblading tools" in addition to a combination of various other methods, such as "ultrasonic cleaner", "cavicide", along with "autoclave" or "UV radiation". Additionally, $100 \%(\mathrm{n}=41)$ of the participants responded "yes" to disposing of pigments and pigment cups after each use, which is another method of infection control in addition to sterilization methods and sanitation.

Respondents were then asked what types of sanitizers they used to clean the work surfaces at their establishment and the majority of them $(58.5 \%, n=24)$ used more than one type of the sanitizers listed: sodium hypochlorite, ethyl or isopropyl alcohol, stabilized hydrogen peroxide, and quaternary ammonium germicide. The other commonly used sanitizers were Cavicide at $17.1 \%(\mathrm{n}=7)$, which is a chemical mixture of isopropanol and diisobutylphenoxyethoxyethyl dimethyl benzyl ammonium chloride (16), sodium hypochlorite solution only $(7.3 \%, \mathrm{n}=3)$ and stabilized hydrogen peroxide only $(7.3 \%$, $n=3$ ), as seen in Figure 4.

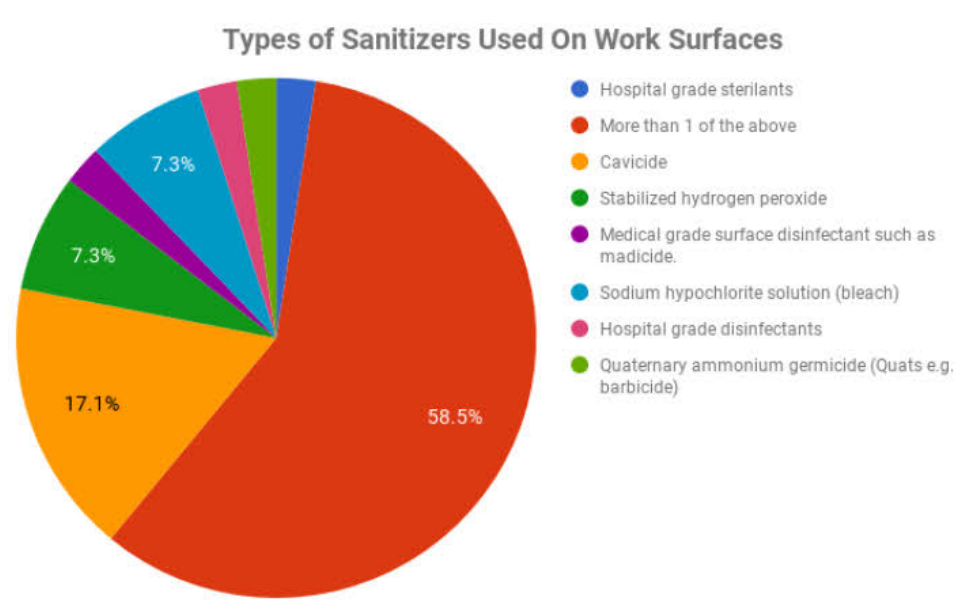

Figure 4. Types of Sanitizers Used on Work Surfaces in Microblading Establishments.

Finally, wound care/aftercare methods were collected from the respondents and most microbladers recommended letting the wound breathe and applying ointment to keep it moist $(53.7 \%, \mathrm{n}=22)$. The next most recommended wound care method was to let the wound breathe while keeping it dry $(9.8 \%, n=4)$, while the other remaining $36.5 \%(n=15)$ recommended a combination of methods or a two part process of letting the wound stay dry for a period of time and then applying ointment later on.

\section{Inferential Statistics:}

Data from the demographic and knowledge components were collected and analyzed in a Chi square test to determine if there is an association between the years of experience and level of pathogen knowledge. Chi square tests are used to interpret the association between nominal and ordinal data (17). 
Table 2. Summary of Inferential Statistics

\begin{tabular}{|c|c|c|c|}
\hline $\mathrm{Ho}$ and $\mathrm{Ha}$ & Test Used & Results & Conclusions \\
\hline $\begin{array}{l}\text { Ho: There is no association } \\
\text { between the years of } \\
\text { experience and the level of } \\
\text { pathogen knowledge }\end{array}$ & Chi square test & $\mathrm{p}=0.78279$ & $\begin{array}{l}\text { Do not reject Ho and conclude there is no } \\
\text { association between the years of experience and } \\
\text { the level of knowledge on pathogens }\end{array}$ \\
\hline $\begin{array}{l}\text { Ha: There is an association } \\
\text { between the years of } \\
\text { experience and the level of } \\
\text { pathogen knowledge }\end{array}$ & & & \\
\hline $\begin{array}{l}\text { Ho: There is no association } \\
\text { between taking a } \\
\text { bloodborne pathogen } \\
\text { course and knowing correct } \\
\text { bloodborne pathogens of } \\
\text { concern. }\end{array}$ & Chi square test & $\mathrm{p}=0.00005$ & $\begin{array}{l}\text { Reject Ho and conclude that there is a statistically } \\
\text { significant association between taking a } \\
\text { bloodborne pathogen course and knowing the } \\
\text { correct bloodborne pathogens of concern }\end{array}$ \\
\hline $\begin{array}{l}\text { Ha: There is an association } \\
\text { between taking a } \\
\text { bloodborne pathogen } \\
\text { course and knowing the } \\
\text { correct bloodborne } \\
\text { pathogens of concern. }\end{array}$ & & & \\
\hline $\begin{array}{l}\text { Ho: There is no association } \\
\text { between attitude towards } \\
\text { regulations regarding } \\
\text { microblading and number } \\
\text { of infection control } \\
\text { measures. }\end{array}$ & Chi square test & $\mathrm{p}=0.38474$ & $\begin{array}{l}\text { Do not reject Ho and conclude there is no } \\
\text { association between attitude towards regulations } \\
\text { regarding microblading and the number of } \\
\text { infection control measures implemented at } \\
\text { microblading establishments }\end{array}$ \\
\hline $\begin{array}{l}\text { Ha: There is an association } \\
\text { between attitude towards } \\
\text { regulations regarding } \\
\text { microblading and number } \\
\text { of infection control } \\
\text { measures. }\end{array}$ & & & \\
\hline
\end{tabular}

The results of the Chi-square tests state that there is no association between years of experience and level of knowledge, nor between the operator's attitude towards regulations regarding microblading and the number of infection control measures in place, as seen in Table 2. However, there is a statistically significant association between taking a bloodborne pathogen course and correctly identifying the main bloodborne pathogens of concern, as the p-value was less than 0.05 , with the p-value of 0.00005 .

\section{Discussion}

According to the results, most microblading technicians had college-level education, 1-5 years of experience in microblading, training in multiple services other than microblading, and had taken a bloodborne pathogen course in the past. The demographics suggest that the majority of microbladers are well educated and have adequate background knowledge about microblading safety due to their experience and education. While $20.5 \%(n=8)$ of microbladers 
received their training through a microblading course that lasted a week or longer, there was also $17.9 \%(n=7)$ who took a 3 -day workshop on microblading as well. This was a concern highlighted in the opinions of microbladers on the adequacy of training requirements, as $78 \%$ $(\mathrm{n}=32)$ thought more training was needed and $78 \%(\mathrm{n}=32)$ of them also do not feel that there is adequate legislation regarding microblading practices in B.C. Currently, there are no specific regulations regarding training or certification for microblading required prior to practice listed in the B.C. Guidelines For Personal Service Establishments or the Microblading Services Fact Sheet $(1,18)$. Furthermore, there are no specific training or certification requirements for the rest of Canada; only annual inspections by the health authorities are required (19). Yet in the U.S., licensing, training, and certification are all required in order to run a personal service establishment, according to the regulations in California and Virginia; however, they are inspected less frequently than annually (19).

The opinions of microbladers towards regulations is congruent with the findings from a previous study on tattoo artists' attitudes towards regulations and practices, which indicated that most of the participants felt positively about regulations and supported having inspections and training requirements by the health authority (20). The participants also felt that only certified professionals should be allowed to buy tattooing equipment and mandatory infection control training should be in place (20). Oberdorfer et al. also found that $95 \%(n=95)$ of tattoo artists studied felt that infection control guidelines were important, and over half of them thought that they could be improved $(21,22)$. This supports the opinions of the microbladers who think that there should be proper training required for microblading as well, instead of the 3-day workshops that are offered.

However, there is no statistically significant association between the attitude towards legislation and the number of infection control measures in place as shown in the Chi-Square Test. This suggests that even though some microbladers may not support having more regulations on microblading, all of them having infection control measures in place, and $90.2 \%$ $(n=37)$ have 5 or more measures, indicating that their attitude has no effect on the amount of infection control measures implemented.

Previous studies do not support this finding; data from several studies have shown that there is higher noncompliance with infection control guidelines when there is low risk of enforcement of regulations or inadequate legislation $(22,23)$.

In terms of sterilization of equipment and sanitation procedures, there appeared to be consistency amongst all microblading operators. Most of them all used single-use disposable blades and one other sterilization method such as an autoclave; in addition, most of them used Cavicide and one other sanitizer to clean their work surfaces. Every single microblader also reported that they disposed of pigments and ink cups after each use as well. This demonstrates that there are standardized methods for proper aseptic/sterilization techniques and common sanitizers accepted among the microblading community. These results suggest that the training received will teach some level of infection control knowledge, supporting the significance of education and training over years of experience.

Additionally, there was no statistically significant association between the years of experience and the level of knowledge on pathogens as calculated by using a Chi-Square test, demonstrating that the microbladers are adequately educated about bloodborne pathogens regardless of how long they have been operating. This is supported by the other Chi-square test which presented a statistically significant association between taking a bloodborne pathogen course, which $85.4 \%$ $(n=34)$ did, and correctly answering which bloodborne pathogens were of concern $(97.6 \%$ $(n=40))$. This verifies that almost all microbladers can identify the bloodborne pathogens irrespective of their years of experience. The irrelevancy in years of experience can potentially be explained by the amount of training the participants have received prior to operating. More than half of the participants have multiple certificates, such as 
BeautySafe, as well as diplomas from cosmetology school. Therefore, many of the new microbladers have received enough education to be equally knowledgeable about infection control and bloodborne pathogens as the more experienced microbladers.

In the study by Raymond et al., it was also found that regulated tattooists had a higher infection control practices score than the nonregulated tattooists (20). The results suggest that tattooists will undertake the required education or certification to successfully perform their jobs regardless of being regulated or not, but nonregulated artists may be less stringent on the number of infection control practices due to lack of enforcement (20). This supports the results of this study because regulated tattooists are required to do training prior to practicing and this includes infection control education. Since they scored higher on infection control practices, whereas non-regulated tattooists are not required to be trained, and thus scored lower, it indicates that it is the level of training and certification which affects pathogen and infection control knowledge and practices, and not necessarily the years of experience.

The main aftercare steps recommended by over half of the microblading technicians were to let the wound breathe and then apply ointment afterwards and all participants advised to seek medical attention if an adverse reaction occurred; the consensus was that the wound needed to stay hydrated. Keeping the wound moist is intended to provide the most effective healing process, as seen in a study which found that a moist environment speeds up healing and is the most effective for minor acute cutaneous wounds, such as cuts in the eyebrows in microblading (11).

The results of this study are only valid when extrapolated to microbladers in B.C. Due to the differences in personal service establishments regulations between each province, the findings are not applicable to the rest of Canada; to do so, participants from each province would have been needed (19). In addition, methodological limitations of the survey affect the validity as well, because there was a small sample size and responses are self-reported and cannot be verified in person.

\section{$\underline{\text { Limitations }}$}

Due to time constraints, funding, and lack of participation, the sample size of the study was limited to a small number of participants. The short time frame allotted for distributing surveys cut off potential participants who could have responded later if the survey was extended and more microbladers could have been contacted as well. Funding was another major limitation which affected the amount of participation, owing to the prize not being of a high monetary value and few winners, there was little incentive to complete the survey. Over 100 microbladers in B.C. were contacted, however, only 41 participants replied, giving a response rate of less than $40 \%$. Participants who feel more positively about regulating the microblading industry could be more inclined to fill out this survey than those who feel negatively towards them also. In addition, due to the nature of the online survey, participants had the ability to check for the correct answer before responding on the survey. This could have resulted in higher test scores that may not represent their true knowledge.

\section{Knowledge Translation}

Data collected from the surveys can be used to help health authorities tailor their inspections for microblading establishments to determine the critical points to look for, such as sterilization methods, sanitation procedures, and their aftercare guidelines. In addition, the positive response towards PSE regulations and desire for more training indicates that the microblading industry would be willing to accept the implementation of more legislation regarding practices, and requirements for certification in order to minimize the number of non-regulated establishments located in private studios and homes. Health authorities can also create more educational courses on infection control and skin conditions and make them requirements for obtaining their business license, because many 
of the microbladers want to be educated on these matters but may not know where to find the information. They could also create a program to cover several topics related to PSEs, such as facility design, operation, disposal, and cleaning, which would standardize the infection control education amongst all PSE operations, as suggested by a previous study by Kat Hansen (24).

\section{Future Research}

- Comparison of knowledge, attitude, and practices on microblading between regulated and non-regulated microblading establishments

- Assessment of knowledge, attitude, and practices on microblading across Canada

- Survey of microblading clients on their experience and opinion on the infection control knowledge and practices of their microblader

- Assessment of the training programs, and comparison of the level of education provided i.e. 3-day workshops compared to 1-week courses

\section{Conclusion}

Microblading is still a relatively new beauty trend that has boomed in popularity over the years and the legislation regarding this practice has still not been created. There have yet to be any scientific studies done on microblading specifically, therefore little is known about their infection control practices and operating procedures. In analyzing the data from this study, it can be concluded that the majority of microbladers are fairly new in the field with only $1-5$ years of experience, have received some form of training, and have taken a bloodborne pathogen course. Most of the participants felt positively about implementing more legislation regarding microblading, and some form of certification requirement in order to practice.

Additionally, there is no association between years of experience and the level of pathogen knowledge, indicating that the education or training is the main source of knowledge. Health authorities should utilize the microblading industry's willingness to accept standardized policies and requirements for operation and create a program for microbladers, and potentially all PSE operators, on public health and infection control in order to create safer PSE environments for everyone. Future research is required to investigate the feasibility of creating a province-wide program, in addition to determining what the training should focus on, such having a larger emphasis on preventative infection controls rather than concurrent measures.

\section{Acknowledgements}

The author would like to acknowledge Dr. Helen Heacock and Elwood Reid for their guidance and knowledge on microblading and other forms of tattooing, and Dr. Angela Eykelbosh (NCCEH) for inspiring this topic of study.

Frederick Shaw (Laboratory Manager, Environmental Health Faculty at BC Institute of Technology) has provided assistance in arranging the prize incentives for the survey participants.

\section{Conflicting Interests}

The authors declare that they have no competing interests in this study. 


\section{$\underline{\text { References }}$}

1. BC Ministry of Health. Microblading Fact Sheet. 2017; Available from: http://www2.gov.bc.ca/assets/gov/health/ keeping-bc-healthysafe/pses/microblading_factsheet_public june13_2017.pdf

2. Juhas E, English JC. Tattoo-Associated Complications. J Pediatr Adolesc Gynecol [Internet]. 2013;26(2):125-9. Available from: http://dx.doi.org/10.1016/j.jpag.2012.08. 005

3. Shinohara MM. Complications of decorative tattoo. Clin Dermatol [Internet]. 2016;34(2):287-92. Available from:

http://dx.doi.org/10.1016/j.clindermatol.2 015.07 .003

4. Kluger N. Cutaneous and systemic complications associated with tattooing. Press Medicale [Internet]. 2016;45(6):567-76. Available from: http://dx.doi.org/10.1016/j.lpm.2016.02.0 16

5. Kazandjieva J, Tsankov N. Tattoos: dermatological complications. Clin Dermatol. 2007;25(4):375-82.

6. Giulieri S, Morisod B, Edney T, Ödman M, Genné D, Malinverni R, et al. Outbreak of Mycobacterium haemophilum Infections after Permanent Makeup of the Eyebrows. Clin Infect Dis. 2017;52(4):488-91.

7. Ortiz AE, Alster TS. Rising concern over cosmetic tattoos. Dermatologic Surg. 2012;38(3):424-9.

8. FDA. Cosmetics facts - Tattoos and Permanent Makeup. US Food Drug Adm [Internet]. 2015;(June):1-2. Available from:
https://www.fda.gov/downloads/Cosmeti cs/ProductsIngredients/Products/UCM46 0321.pdf

9. BC Ministry of Health. Guidelines for Body Modification Health Protection Branch. 2014.

10. Watson K. Microblading: Aftercare and Safety Tips [Internet]. Healthline. 2017 [cited 2017 Oct 20]. Available from: https://www.healthline.com/health/micro blading\#skincare-after-microblading2

11. Korting HC, Schöllmann C, White RJ. Management of minor acute cutaneous wounds: Importance of wound healing in a moist environment. J Eur Acad Dermatology Venereol. 2011;25(2):130 7.

12. Microsoft. No Title. Microsoft Corporation; 2016.

13. Hintze J. NCSS 11 Statistical Software [Internet]. Kaysville; 2016. Available from: ncss.com/software/ncss

14. Yelp. Microblading in Vancouver [Internet]. 2017 [cited 2017 Nov 26]. Available from: https://www.yelp.ca/vancouver

15. Heuvel M Van Den. Research Ethics Board ( REB ). 2016;(July 2013):4-5.

16. Metrex. Material Safety Data Sheet: Cavicide [Internet]. 2015. p. 1-6.

Available from: https://www.metrex.com/sites/default/file s/content/education-file/education-fileupload/CaviCide Canadian MSDS (7-142015).pdf

17. Schumacker R, Tomek S. Understanding Stats via R. Vol. 53, Journal of Chemical Information and Modeling. 2013. 1689$1699 \mathrm{p}$.

18. BC Ministry of Health. Guidelines for 
Personal Service Establishments. 2013;(November).

19. Rideout K (NCCEH). Comparison of Guidelines and Regulatory Frameworks for Personal Services Establishments. 2010;(July):1-13. Available from: http://ccnse.ca/sites/default/files/PSE_Gu idelines_Comparison_Table_July_2010.p df

20. Raymond, M J; Halcon, Linda; Pirie P. Regulation of Tattooing in Minneapolis and St . Paul, Minnesota : Tattooists, Attitudes and Relationship Between Regulation and Practice. Public Heal reports (Washington, DC 2003). 2003;118(April):154-61.

21. Keller F. The Relationships Among Knowledge, Attitudes, Subjective Norms, and Intentions Regarding Tattooing in Current and Prospective Tattoo Clients. 2013.

22. Oberdorfer A, Wiggers JH, Bowman J,
Lecathelinais C. Infection control practices among tattooists and body piercers in Sydney, Australia. Am J Infect Control. 2003;31(8):447-56.

23. Oberdorfer A, Wiggers $\mathrm{JH}$, Considine RJ, Bowman J, Cockburn J. Skin penetration operators' knowledge and attitudes towards infection control. Am J Health Behav. 2003;27(2):125-34.

24. Hansen K. The public health impact of infection control, sterilization and regulation in tattooing. 2017;(April). Available from:

https://circuit.bcit.ca/repository/islandora /object/repository\%3A393/datastream/P $\mathrm{DF} /$ view

25. Wong E. Biological Hazards Associated with Microblading and Evaluation of its Infection Control Procedures and Wound Care. BCIT Environ Heal J [Internet]. 2018; Available from: https:/circuit.bcit.ca/repository/islandora /object/repository\%3Aenvh_journal 